\title{
Metabolism of alkaloids in coffee plants
}

\author{
Hiroshi Ashihara
}

Metabolic Biology Group, Department of Biology, Faculty of Science, Ochanomizu University, Tokyo, 112-8610, Japan; E-mail: ashihara@cc.ocha.ac.jp

Coffee beans contain two types of alkaloids, caffeine and trigonelline, as major components. This review describes the distribution and metabolism of these compounds. Caffeine is synthesised from xanthosine derived from purine nucleotides. The major biosynthetic route is xanthosine $\rightarrow 7$-methylxanthosine $\rightarrow 7$-methylxanthine $\rightarrow$ theobromine $\rightarrow$ caffeine. Degradation activity of caffeine in coffee plants is very low, but catabolism of theophylline is always present. Theophylline is converted to xanthine, and then enters the conventional purine degradation pathway. A recent development in caffeine research is the successful cloning of genes of $\mathrm{N}$-methyltransferases and characterization of recombinant proteins of these genes. Possible biotechnological applications are discussed briefly. Trigonelline ( $N$-methylnicotinic acid) is synthesised from nicotinic acid derived from nicotinamide adenine nucleotides. Nicotinate $N$-methyltransferase (trigonelline synthase) activity was detected in coffee plants, but purification of this enzyme or cloning of the genes of this $N$-methyltransferase has not yet been reported. The degradation activity of trigonelline in coffee plants is extremely low.

Key words: Coffea, caffeine, purine alkaloids, pyridine alkaloids, theobromine, trigonelline.

Metabolismo de alcalóides em plantas de café: Sementes de café possuem dois tipos de alcalóides, cafeína e trigonelina, como principais componentes. Esta revisão descreve a distribuição e metabolismo desses compostos. Cafeína é sintetizada a partir da xantosina derivada de nucleotídeos purínicos. A principal rota biossintética é xantosina $\rightarrow 7$-metilxantosina $\rightarrow 7$-metilxantina $\rightarrow$ teobromina $\rightarrow$ cafeína. A atividade de degradação de cafeína em café é muito baixa, mas o catabolismo de teofilina está sempre presente. Teofilina é convertida a xantina, que entra na via convencional de degradação de purinas. Um recente desenvolvimento na pesquisa com cafeína é a clonagem de genes de $N$-metiltransferases e a caracterização de proteínas recombinantes desses genes. Possíveis aplicações biotecnológicas são discutidas brevemente. Trigonelina (ácido $N$-metilnicotínico) é sintetizada a partir de ácido nicotínico derivado de nucleotídeos de nicotinamida adenina. Atividade de nicotinato $N$-metiltransferase (trigonelina sintase) foi detectada em plantas de café, mas a purificação desta enzima ou a clonagem dos genes desta $N$-metiltransferase ainda não foi relatada na literatura. A atividade de degradação de trigonelina em café é extremamente baixa.

Palavras-chave: Coffea, alcalóides purínicos, alcalóides piridínicos, cafeína, teobromina, trigonelina.

\section{INTRODUCTION}

Coffee plants contain two different kinds of alkaloid delivered from nucleotides. One type is purine alkaloids, such as caffeine (1,3,7- $N$-trimethylxanthine) and theobromine (3,7- $N$-dimethylxanthine); the other is the pyridine alkaloid, trigonelline (1- $N$-methylnicotinic acid). The distribution of caffeine and trigonelline in the plant kingdom is different; caffeine is present in both coffee and tea, but trigonelline is found only in coffee. Large amounts of trigonelline are also found in many leguminous plants. Although the metabo- lism of purine and pyridine alkaloids has been investigated in several plants, the present review focuses mainly on coffee plants. There are many species of Coffea plant, but the term 'coffee plant' is used here for Coffea arabica or Coffea canephora plants.

\section{Purine alkaloids}

Distribution of purine alkaloids: Purine alkaloids are distributed in 13 orders of plants within the plant kingdom. By the end of the 20th century, caffeine had been found 
in nearly 100 plant species. Caffeine is the most common purine alkaloid, but in a few plant species including cacao and unique Chinese tea plants, the main purine alkaloid is theobromine or methyluric acid (Ashihara and Crozier, 1999; Ashihara and Suzuki, 2004). A large amount of caffeine is found in coffee seeds (mainly in endosperms). The caffeine content of coffee beans is usually expressed as percentage of dry weight. The beans of most cultivars of Arabica coffee (Coffea arabica) contain up to $1.0 \%$ caffeine, but Robusta coffee (Coffea canephora) contain about $2 \%$ caffeine. Although these species are not commonly used for beverages, Coffea dewevrei (1.2\%) and Coffea liberica $(1.4 \%)$ also contain high concentrations of caffeine. In contrast, the caffeine content of seeds of Coffea eugenioides (0.4\%), Coffea salvatrix (0.7\%) and Coffea racemosa $(0.8 \%)$, are low (Mazzafera, 1992). Mascarocoffea has been thought to be free purine alkaloid, but theobromine (up to $0.14 \%$ ) and caffeine (up to $0.76 \%$ ) has been found in two populations of Coffea lancifolia and in one population of Coffea kianjavatensis (Rakotomalala et al., 1992).

As well as in seeds, caffeine is distributed in the pericarp of fruits and leaves of coffee plants. In coffee seedlings, caffeine is distributed mainly in leaves and cotyledons, and essentially no caffeine was detected in roots or in older brown parts of shoots (Zheng and Ashihara, 2004). It has been proposed that caffeine is sequestered in the vacuoles of coffee leaves as a chlorogenic acid complex (Aerts and Baumann, 1994). Mature leaves of Coffea liberica, Coffea dewevrei and Coffea abeokutae convert caffeine to methyluric acids: theacrine (1,3,7,9-tetramethyluric acid), liberine $(O(2), 1,9$-trimethyluric acid) and methylliberine $(O(2), 1,7,9$-tetramethyluric acid) (Petermann et al., 1983).

Biosynthesis of purine alkaloids: The xanthine skeleton of caffeine is derived from purine nucleotides. Xanthosine is the initial purine compound in the caffeine biosynthetic pathway, acting as a substrate for a methyl group donated by $S$-adenosyl-1-methionine (SAM). There are at least four routes from purine nucleotides to xanthosine. Evidence suggests that the important ones are the production of xanthosine (i) from IMP derived from the de novo purine nucleotide biosynthesis, (ii) from adenosine released from the SAM cycle (also known as the activated-methyl cycle), (iii) from the adenine nucleotide pool, and (iv) from the guanine nucleotide pool (Suzuki et al., 1992; Ashihara and Crozier, 1999; 2001) (figure 1). Tracer experiments with labelled precursors and leaf discs from coffee and tea plants have shown that the major route to caffeine is a xanthosine $\rightarrow$ 7-methylxanthosine $\rightarrow$ 7-methylxanthine $\rightarrow$ theobromine $\rightarrow$ caffeine pathway; alternative minor routes might also be operative (Kato et al., 1996) (figure 2). Ashihara and Suzuki (2004) classified two groups of metabolic routes of caffeine biosynthesis: the "provider pathways" that provide xanthosine for caffeine biosynthesis, and a "core pathway" that involves three $N$-methyltransferases and a nucleosidase. Here, we describe the enzymes and the corresponding genes of the "core pathway".

7-Methylxanthosine synthase: The first methylation step in the biosynthetic pathway of caffeine is the conversion of xanthosine to 7-methylxanthosine. This is catalysed by an $N$-methyltransferase, 7-methylxanthosine synthase (SAM:

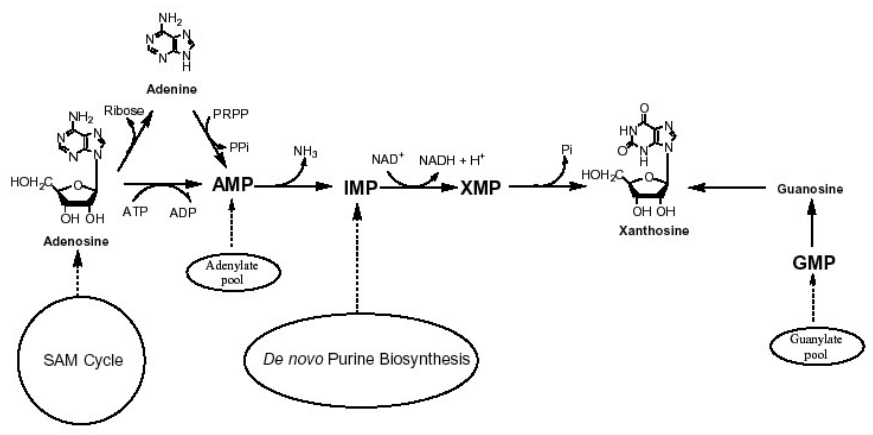

Figure 1. The "provider pathways" for xanthosine. Caffeine biosynthesis starts with the methylation of xanthosine. There are several pathways which provide xanthosine for caffeine synthesis.

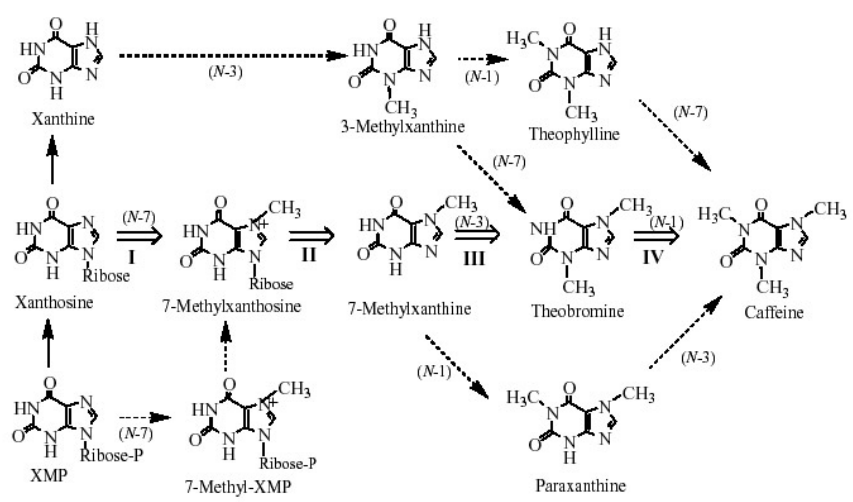

Figure 2. The "core pathway" of caffeine. The main pathway involves three-methylation steps (I, III and IV), and one nucleosidase reaction. $\mathrm{N}-1, \mathrm{~N}-3, \mathrm{~N}-7$ indicates the position of the nitrogen atom in the purine ring that is methylated. Minor pathways are shown by arrows with dotted lines. These minor routes are probably due to the broad substrate specificity of $N$-methyltransferases. 
xanthosine $N$-methyltransferase). In coffee leaf extracts, 7-methylxanthosine synthase exhibited high substrate specificity for xanthosine as the methyl acceptor and SAM as the methyl donor (Roberts and Waller, 1979). 7-Methylxanthine synthase is extremely labile in extracts. However, $10 \mathrm{mM}$ dithiothreitol and 20\% ethylene glycol (or glycerol) stabilise the activity (Gilles et al. 1995). Mosli Waldahauser et al. (1997) have purified 7-methyl-XMP/7-methylxanthine synthase from coffee leaves, using ammonium sulphate precipitation, anion-exchange (Q-Sepharose) chromatography, chromatofocusing (Mono-P), and gel filtration chromatography (Superdex 200). Purification was difficult even with the stabiliser of the enzyme mentioned above, so that the specific activity of the enzyme in the final preparation was low (19 pkat per mg protein) and purification was only 9fold. The purified enzyme was able to convert xanthosine to 7-methylxanthosine. These authors also mentioned the enzyme that converted XMP to 7-methylxanthosine via 7-methylXMP. In fact, their enzyme preparation showed nucleosidase activity. It is therefore possible that XMP was converted to xanthosine and used as substrate; however, these authors believe that XMP is the real substrate, and that 7-methylXMP was converted to 7-methylxanthosine. They mentioned in the text that trace amounts of 7-methylXMP were detected.

Recently, the genes encoding 7-methylxanthosine synthase were cloned by two Japanese groups (Mizuno et al, 2003; Uefuji et al., 2003). The genes isolated were respectively CmXRS1 (AB 034699) and CaXMT1 (AB048793).

The recombinant proteins of 7-methylxanthosine synthase from both groups catalyse the conversion of xanthosine to 7-methylxanthosine, but XMP is not used as a substrate. Although the presence of the other gene that encodes 7-methyl-XMP synthase cannot be excluded, current evidence supports the hypothesis that caffeine biosynthesis is begins with xanthosine.

7-Methylxanthine nucleosidase: N-Methylnucleosidase, which catalyses the hydrolysis of 7-methylxanthosine to give 7-methylxanthine, has been purified from tea leaves (Negishi et al., 1988). However, isolation of the native enzyme as well as RNA encoding this enzyme has not yet been reported in coffee plants.

Theobromine synthase and caffeine synthase: Bifunctional caffeine synthase, which catalyses both the conversion of 7-methylxanthine to theobromine and theobromine to caffeine, was first purified from tea leaves up to apparent homogeneity (Kato et al., 1999). This enzyme is monomeric, with an apparent molecular mass of $41 \mathrm{kDa}$, and displays a sharp $\mathrm{pH}$ optimum of $\mathrm{pH}$ 8.5. The total length of the isolated cDNA, termed TCS1 (AB031280), is 1,438 bp and encodes a protein of 369 amino acids (Kato et al., 2000). In coffee, bifunctional caffeine synthase has been partially purified from fruits and leaves by Mazzafera et al. (1994). This enzyme preparation possessed second and third $N$ methyltransferase activity.

In coffee, genes encoding two types of $N$-methyltransferase for the last two steps of caffeine biosynthesis have recently been reported (Mizuno et al., 2001; 2003; Uefuji et al., 2003). These are CTS1 (AB034700), CaMXMT1 (AB048796), CCS1 (AB086414) and CaDXMT1 (AB084125). As shown in Table 1, substrate specificity of the recombinant theobromine synthase is specific for theobromine synthesis (step 2), but the recombinant caffeine synthase utilises paraxanthine, theobromine and 7-methylxanthine, as in the native tea caffeine synthase (Kato et al., 1999). Although paraxanthine is the most suitable substrate, formation of paraxanthine in coffee plant tissues in vivo seems to be very restricted. Therefore, this enzyme seems to contribute to the conversion of 7-methylxanthine to caffeine via theobromine in planta.

Caffeine biosynthesis in coffee leaves: Caffeine is synthesised in young leaves of Coffea arabica, but its biosynthetic activity from adenine is absent in fully developed leaves (Fujimori and Ashihara, 1994). It has been proposed that the synthesis of caffeine in buds and leaves of coffee plants is to prevent predation by animals (Frischknecht et al., 1986). Ashihara et al. (1996) reported that caffeine biosynthesis from adenine and guanine was only found in young leaves, but conversion of theobromine and caffeine was found in mature and aged coffee leaves. Caffeine synthase activity therefore seems to be present in coffee leaves even after maturation. This is different from tea leaves, in which caffeine synthase activity disappeared after full development of the leaves (Fujimori et al., 1991).

Caffeine biosynthesis in coffee fruits: Biosynthesis of caffeine can be estimated from the incorporation of [methyl$\left.{ }^{14} \mathrm{C}\right]$ methionine. It occurs mainly during the immature green stage of coffee fruit development (Suzuki and Waller, 1984). More detailed studies have recently been made by Koshiro et al. (2006) using two varieties of Coffea arabica and one 
variety of Coffea canephora grown in the same field in Hawaii. Their data indicate that caffeine biosynthetic activity, as estimated from the incorporation of $\left[8-{ }^{14} \mathrm{C}\right]$ adenine into theobromine and caffeine, is higher in pericarps and seeds of fruits in the early stages of development than in the later stages. However, expression of the caffeine synthase gene, estimated by RT-PCR, was found in all stages of coffee fruit development up to the pre-maturation stage (Koshiro et al., 2006).

Degradation of caffeine: As stated above, caffeine is produced in young leaves and immature fruits, and continues to accumulate gradually during the maturation of these organs. However, it is very slowly degraded with the removal of the three methyl groups, resulting in the formation of xanthine (figure 3). Xanthine is further degraded by the conventional purine catabolism pathway to $\mathrm{CO}_{2}$ and $\mathrm{NH}_{3}$ via uric acid, allantoin and allantoate. A detailed review of catabolism of caffeine in plants and microorganisms has been published by Mazzafera (2004). Since exogenously supplied [8$\left.{ }^{14} \mathrm{C}\right]$ theophylline is degraded to $\mathrm{CO}_{2}$ far more rapidly than $\left[8-{ }^{14} \mathrm{C}\right]$ caffeine, the initial step, namely the conversion of caffeine to theophylline, seems to be the major rate-limiting step of caffeine catabolism (Ashihara et al., 1996; Ito et al., 1997). In leaves of Coffea eugenioides, a low caffeinecontaining species, $\left[8-{ }^{14} \mathrm{C}\right]$ caffeine was degraded rapidly, and much of the radioactivity was recovered as ${ }^{14} \mathrm{CO}_{2}$ (Ashihara and Crozier, 1999). Coffea eugenioides therefore possessed far higher levels of caffeine demethylase activity, and is able to convert endogenous caffeine efficiently to theophylline, which is rapidly degraded further. However, attempts to detect caffeine demethylase activity in the extracts in vitro are have still been unsuccessful (Ashihara and Crozier, unpublished result).

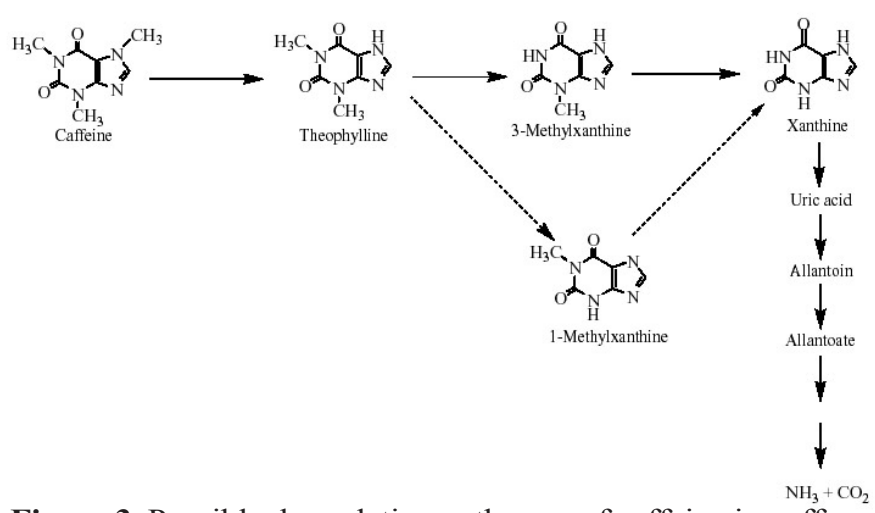

Figure 3. Possible degradation pathways of caffeine in coffee plants. The major pathway is shown in arrows with a solid line, and minor routes with a dotted line.
Biotechnology of caffeine: In economic terms, coffee is one of the most valuable agricultural products exported by developing countries in Central and South America, Southeast Asia and Africa. Beans of Arabica and Robusta coffee respectively contain ca. $1 \%$ and $2 \%$ caffeine. Since the early 1970s, the demand for decaffeinated coffee has increased rapidly. This is because of a growing belief that ingestion of large amounts of caffeine has adverse effects on health. This has led to extensive debate in the medical literature, although no clear conclusions have been drawn (Ashihara and Crozier, 2001). The use of genetic engineering to produce transgenic caffeine-deficient coffee has been investigated. Genes encoding $N$-methyltransferases have been cloned. This development makes it possible by genetic engineering to produce transgenic coffee plants that are naturally deficient in caffeine. The use of such products to make full flavoured caffeine-free beverages will be of interest to the increasing number of consumers who are concerned about the adverse effects of caffeine consumption, such as insomnia. The cloning of genes related to caffeine biosynthesis ( $N$-methyltransferase genes) is an important advance towards the production of transgenic caffeine-deficient coffee through gene silencing with RNA interference technology. Recently, using nucleotide sequences of genes encoding $N$ methyltransferases for caffeine biosynthesis, transgenic caffeine-deficient Coffea canephora plants have been created (Ogita et al., 2003).

The preparation of a low caffeine good quality tea using gene silencing of other genes has been attempted. Keya et al. (2003) suggested that suppression of IMP dehydrogenase gene expression is an alternative way to produce decaffeinated transgenic tea and coffee plants. It is currently believed that the tea-specific amino acid, theanine, makes a major contribution to umami taste, which is quite distinct from four basic tastes (Koshiishi et al., 2001). IMP may also be involved, since nucleotide seasonings are known to interact synergistically with amino acid-based tastes. Purine nucleotides in fresh tea leaves may be converted to IMP during commercial processing. Metabolic engineering to accumulate IMP and related nucleotides would therefore be of value. Kaya et al. indicate that caffeine synthesis should be reduced and that free purine nucleotides, including IMP, will accumulate if IMPDH activity is blocked. Transgenic tea plants with reduced IMPDH activity therefore offer the intriguing prospect of a beverage with low caffeine content coupled with enhanced flavour quality. 


\section{Pyridine alkaloids}

Distribution of trigonelline: Trigonelline was first isolated from fenugreek (Trigonella foenum-graecum) (Johns, 1885), and is found in various plants and in some animal species including sea urchins and jellyfish. It also appears in mammalian urine after administration of nicotinic acid (Scheline, 1991). In coffee seeds, the concentration of trigonelline is ca. 2\% of dry weight (Clifford, 1985; Mazzafera, 1991). Trigonelline in raw coffee materials ('green beans') is thermally converted to nicotinic acid and to certain flavour compounds during roasting (Mazzafera, 1991).

Biosynthesis of pyridine alkaloids: The direct precursor of trigonelline is nicotinic acid (Joshi and Handler, 1960). In plants, nicotinic acid is produced as a degradation product of NAD (Wagner and Backer, 1992; Zheng and Ashihara, 2004) (figure 4). Zheng and Ashihara (2004) have reported that trigonelline and its metabolic synthesis from $\left[{ }^{14} \mathrm{C}\right]$ nicotinic acid are distributed in all parts of coffee seedlings. The de novo and salvage pathways of NAD synthesis have been investigated in several plants (figure 5). In bacteria and plants, quinolinic acid, an intermediate of the de novo pathway, is synthesised from aspartate and triose phosphate via the so-called aspartate pathway (Yang and Waller, 1965; Katoh and Hashimoto, 2004). In contrast, quinolinic acid is formed in animals by a tryptophane-kynurenine pathway. A recent bioinformatic search of genome databases suggests that the tryptophane-kynurenine pathway is present in the Oryza sativa (Katoh and Hashimoto, 2004). No genome database concerning pyridine nucleotide metabolism has been published in coffee. Nicotinamide and nicotinic acid formed by NAD degradation pathways are re-utilized (salvaged) for NAD synthesis (Wagner et al., 1986; Ashihara et al., 2005; Zheng et al., 2005). The routes of degradation and salvage of pyridine compounds have been called the pyridine nucleotide cycle (figure 5). There are several distinct cycles in different organisms.

Zheng et al. (2004) studied the metabolism of $\left[{ }^{3} \mathrm{H}\right]$ quinolinic acid, $\left[{ }^{14} \mathrm{C}\right]$ nicotinamide, and $\left[{ }^{14} \mathrm{C}\right]$ nicotinic acid in leaves and fruits of Coffea arabica. Their data suggest that, in addition to the de novo pathway for NAD synthesis, the six membered pyridine nucleotide cycle (PNC $\mathrm{VI}), \mathrm{NAD} \rightarrow \mathrm{NMN} \rightarrow$ nicotinamide $\rightarrow$ nicotinic acid $\rightarrow$ $\mathrm{NaMN} \rightarrow \mathrm{NaAD} \rightarrow \mathrm{NAD}$ operates in coffee plants, as in tobacco plants (Wagner et al., 1986). Some minor pathways may also be operative in part; for example, nicotinamide may be also produced from NAD by an ADP-ribosylation reaction, and $\mathrm{NaMN}$ may be formed by an alternative route from nicotinic acid (Zheng et al., 2004). (Fig. 3).

Degradation of NAD by the pyridine nucleotide cycle is the major source of nicotinic acid, although direct nicotinic acid formation from NaMN formed by the de novo pyridine nucleotide biosynthesis cannot be excluded. Trigonelline is produced when nicotinic acid is in excess for pyridine nucleotide synthesis.

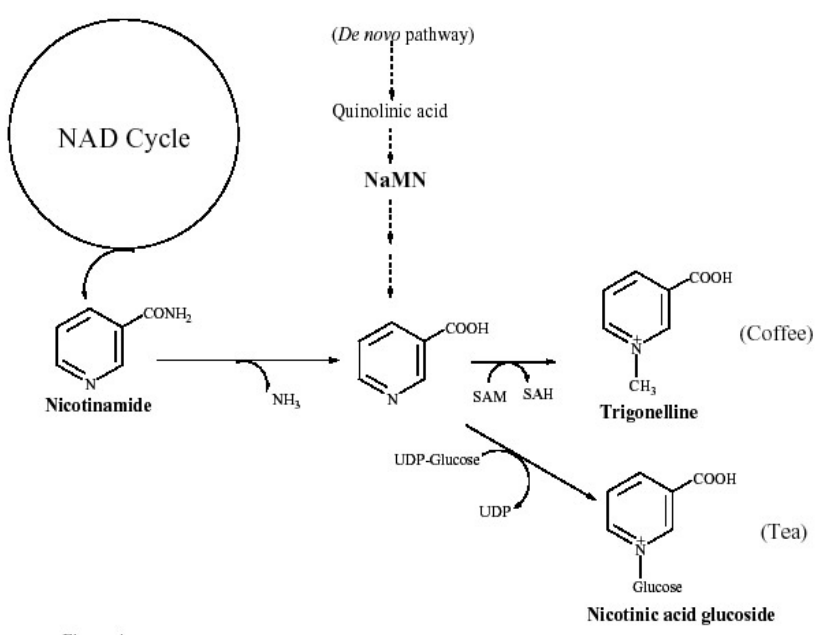

Figure 4. Biosynthesis of trigonelline in coffee plants. Trigonelline is synthesised by a one step reaction from nicotinic acid, which is provided by the NAD cycle. However, direct production from quinolinic acid may be an alternative path to nicotinic acid. In tea plants, nicotinic acid is converted to nicotinic acid glucoside, but not to trigonelline.

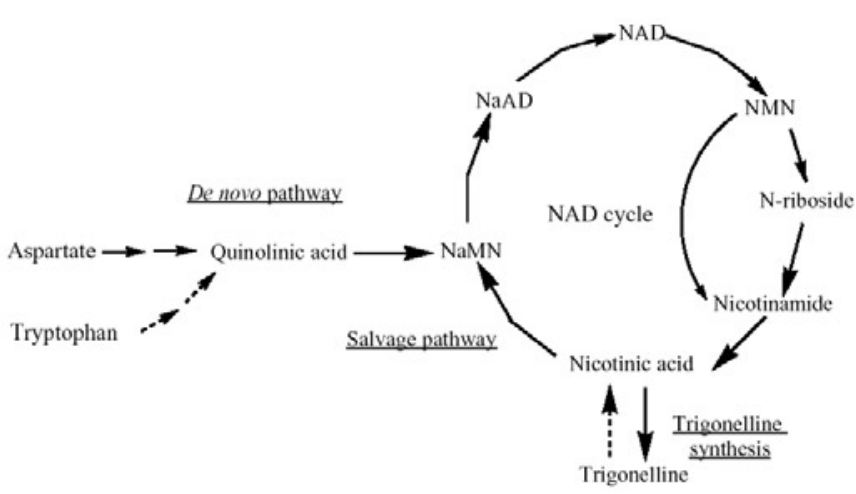

Figure 5. The NAD cycle and trigonelline synthesis in coffee. Nicotinic acid mononucleotide (NaMN) is synthesised by the de novo pathway and is utilised for the synthesis of NAD; NAD is degraded, and pyridine skeletons are recovered as nicotinamide mononucleotide (NMN) following which nicotinamide is released. After conversion to nicotinic acid, this is utilised for the synthesis of NaMP and trigonelline. A small amount of trigonelline accumulated in coffee seeds may be demethylated to nicotinic acid and utilised for NAD synthesis in the early stage of germination. 
For comparison, metabolism of $\left[{ }^{14} \mathrm{C}\right]$ nicotinamide was examined in other purine alkaloid-accumulating plants. Both trigonelline and nicotinic acid glucoside were formed in Theobroma cacao, but only nicotinic acid glucoside was synthesized in Camellia sinensis. Little or no trigonelline accumulates in cacao fruits or tea leaves (Zheng et al., 2004).

Trigonelline synthase: Trigonelline is synthesized by $S$ adenosyl-L-methionine (SAM) dependent nicotinate $\mathrm{N}$ methyltransferase (EC 2.1.1.7), which has been found in crude extracts of the pea (Joshi and Handler 1960). This enzyme has been purified from cultured Glycine max cells (Upmeier et al., 1988) and Lemna paucicostata (Taguchi et al., 1989). Although nicotinic acid $N$-methyltransferase (trigonelline synthase) activity was detected in a cell-free preparation from coffee (Taguchi et al., 1987), no purification has been carried out. The gene encoding trigonelline synthase has not yet been cloned from any organism.

Trigonelline biosynthesis in coffee leaves: The content and concentrations of trigonelline and the metabolic profiles of $\left[{ }^{14} \mathrm{C}\right]$ nicotinamide have been studied in leaves and fruits of Coffea arabica at different stages of growth (Zheng and Ashihara 2004; Zheng et al., 2004). Trigonelline accumulates during leaf development. Correspondingly, high biosynthetic activity of trigonelline from [carbonyl- ${ }^{14} \mathrm{C}$ ] nicotinamide was found in developing leaves. In young coffee leaves, NAD biosynthesis de novo and the pyridine nucleotide cycle may both be highly active. Nicotinic acid formed from NAD via nicotinamide may be preferentially utilised for NAD formation, and the remainder converted to trigonelline. After maturation of leaves there is no massive accumulation of trigonelline; only a small amount of trigonelline was found in detached senescent leaves. Although in situ biosynthetic activity was found even in aged leaves, based on the incorporation of radioactivity from [carbonyl${ }^{14} \mathrm{C}$ ] nicotinamide to trigonelline, the endogenous supply of nicotinamide in aged leaves may be limited because of the fall in pyridine nucleotide cycle activity. As a result, biosynthesis of trigonelline declines in aged leaves.

Trigonelline biosynthesis in coffee fruits: Trigonelline accumulates in fruits of Coffea arabica during growth, and accumulates finally in seeds. In the dry matter accumulation stage of the bean, according to the classification of Cannell (1985), high biosynthetic activity of trigonelline is found in the pericarp, although some activity was also found in seeds.
In the fruit ripening stage, biosynthetic activity decreases markedly. This suggests that net biosynthesis of trigonelline takes place in the young pericarp, and trigonelline may be transported from the pericarp to seeds (Zheng et al., 2004, Koshiro et al., 2006).

Degradation of trigonelline: In planta, trigonelline is demethylated to nicotinic acid and utilized for NAD synthesis. Trigonelline demethylating activity has been found in extracts of some plant leaves, including pine leaves (Taguchi and Shimabayashi, 1983).

Shimizu and Mazzafera (2000) investigated changes in the trigonelline content of coffee seeds during the very early stages of germination. Trigonelline accumulated in seeds is converted to nicotinic acid during germination, and is used for the NAD synthesis. In this case, trigonelline acts as a reservoir of nicotinic acid in plants.

Part of the nicotinic acid formed from trigonelline is further degraded. Willeke et al. (1979) stated that degradation of nicotinic acid could be observed only in cell cultures producing the sugar conjugates of nicotinic acid, and that nicotinic acid degradation does not involve free 6 hydroxynicotinic acid. However, the degradation route(s) of pyridine ring of trigonelline in plants is still unclear.

Biotechnology of trigonelline: Trigonelline is one of the candidates responsible for bitter tasting compounds in the coffee brew (Homma, 2001). It is thermally unstable and is converted by roasting to nicotinic acid and other nitrogenous materials that include flavour compounds. In the future, metabolic engineering of trigonelline formation could therefore be a useful technology to create good quality coffee beans.

\section{REFERENCES}

Aerts RJ, Baumann TW (1994) Distribution and utilization of chlorogenic acid in developing Coffea seedlings. J. Exp. Bot. 45: 497-503.

Ashihara H, Crozier A (1999a) Biosynthesis and catabolism of caffeine in low-caffeine-containing species of Coffea. J. Agric. Food Chem. 47: 3425-3431.

Ashihara H, Crozier A (1999b) Biosynthesis and metabolism of caffeine and related purine alkaloids in plants. Adv. Bot. Res. 30: 118-205.

Ashihara H, Monteiro AM, Gillies FM, Crozier A (1996) Biosynthesis of caffeine in leaves of coffee. Plant Physiol. 111: 747-753.

Ashihara H, Monteiro AM, Moritz T, Gillies FM, Crozier A (1996) Catabolism of caffeine and related purine alkaloids in leaves of Coffea arabica L. Planta 198: 334-339. 
Ashihara H, Suzuki T (2004) Distribution and biosynthesis of caffeine in plants. Front. Biosci. 9: 1864-1876.

Ashihara H, Crozier A (2001) Caffeine: a well known but little mentioned compound in plant science. Trends Plant Sci. 6: 407-413.

Ashihara H, Stasolla C, Yin Y, Loukanina N, Thorpe TA(2005) De novo and salvage biosynthetic pathways of pyridine nucleotides and nicotinic acid conjugates in cultured plant cells. Plant Sci. 169: 107-114.

Cannell MGR (1985) Physiology of the coffee crop. In: Clifford MN, Willson KC (eds), Coffee: botany, biochemistry and production of beans and beverage, pp. 108-134. Croom Helm, London.

Clifford MN (1985) Chemical and physical aspects of green coffee and coffee products. In: Clifford MN, Willson KC (eds), Coffee: botany, biochemistry and production of beans and beverage, pp. 305-374. Croom Helm, London.

Frischknecht PM, Ulmer-Dufek J, Baumann TW (1986) Purine alkaloid formation in buds and developing leaflets of Coffea arabica: Expression of an optimal defence strategy? Phytochemistry 25: 613-616.

Fujimori N, Ashihara H (1994) Biosynthesis of theobromine and caffeine in developing leaves of Coffea arabica. Phytochemistry 36 : 1359-1361.

Fujimori N, Suzuki T, Ashihara H (1991) Seasonal variations in biosynthetic capacity for the synthesis of caffeine in tea leaves. Phytochemistry 30: 2245-2248.

Ito E, Crozier A, Ashihara H (1997) Theophylline metabolism in higher plants. Biochim. Biophys. Acta 1336: 323330.

Johns E (1885) Ueber die Alkaloide des Bockshornsamens. Ber. Deut. Chem. Ges. 18: 2518-2523.

Joshi JG, Handler P (1960) Biosynthesis of trigonelline. J. Biol. Chem. 235: 2981-2983.

Kato M, Kanehara T, Shimizu H, Suzuki T, Gillies FM, Crozier A, Ashihara H (1996) Caffeine biosynthesis in young leaves of Camellia sinensis: In vitro studies on $N$-methyltransferase activity involved in the conversion of xanthosine to caffeine. Physiol. Plant. 98: 629-636..

Kato M, Mizuno K, Crozier A, Fujimura T, Ashihara H (2000) A gene encoding caffeine synthase from tea leaves. Nature 406: 956-957.

Kato M, Mizuno K, Fujimura T, Iwama M, Irie M, Crozier A, Ashihara H (1999) Purification and characterization of caffeine synthase from tea leaves. Plant Physiol. 120: 597586.

Katoh A, Hashimoto T (2004) Molecular biology of pyridine nucleotide and nicotine biosynthesis. Front. Biosci. 9: 1577-1586.

Keya CA, Crozier A, Ashihara H (2003) Inhibition of caffeine biosynthesis in tea (Camellia sinensis) and coffee (Coffea arabica) plants by ribavirin. FEBS Lett. 554: 473-477.

Koshiiro C, Crozier A, Ashihara H (2001) Profiles of purine and pyrimidine nucleotides in fresh and manufactured tea leaves J. Agric. Food Chem. 49:4378-4382.

Koshiiro Y, Zheng XQ, Wang M, Nagai C, Ashihara H (2006) Changes in content and biosynthetic activity of caffeine and trigonelline during growth and ripening of Coffea arabica and Coffea canephora. Plant Sci - in press

Mazzafera P (2004) Catabolism of caffeine in plants and microorganisms. Front. Biosci. 9: 1348-1359.

Mazzafera P, Carvalho A (1992) Breeding for low seed caffeine content of coffee (Coffea L.) by interspecific hybridization. Euphytica 59: 55-60

Mazzafera P (1991) Trigonelline in coffee. Phytochemistry 30: 2309-2310.

Mazzafera P, Wingsle G, Olsson O, Sandberg G (1994) S-adenosylmethionine:Theobromine 1-N-methyltransferase an enzyme catalysing the synthesis of caffeine in coffee. Phytochemistry 37: 1577-1584.

Mizuno K, Okuda A, Kato M, Yoneyama N, Tanaka H, Ashihara H, Fujimura T (2003) Isolation of a new dual-functional caffeine synthase gene encoding an enzyme for the conversion of 7-methylxanthine to caffeine from coffee (Coffea arabica L.). FEBS Lett. 534: 75-81.

Mizuno K, Kato M, Irino F, Yoneyama N, Fujimura T, Ashihara H (2003) The first committed step reaction of caffeine biosynthesis: 7-methylxanthosine synthase is closely homologous to caffeine synthases in coffee (Coffea arabica L.). FEBS Lett. 547: 56-60.

Mizuno K, Tanaka H, Kato M, Ashihara H, Fujimura T (2001) cDNA cloning of caffeine (theobromine) synthase from coffee (Coffea arabica L.). Colloq. Sci. Int. Café 19: 815-818.

Negishi O, Ozawa T, Imagawa H (1988) N-methylnucleosidase from tea leaves. Agric. Biol. Chem. 52: 169-175.

Ogita S, Uefuji H, Yamaguchi Y, Koizumi N, Sano H (2003) Producing decaffeinated coffee plants. Nature 423: 823.

Petermann J, Baumann TW (1983) Metabolic relations between methylxanthines and methyluric acids in Coffea. Plant Physiol. 73: 961-964.

Rakotomalala JJ, Cros E, Clifford MN, Charrier A (1992) Caffeine and theobromine in green beans from Mascarocoffea. Phytochemistry 31: 1271-1272.

Roberts MF, Waller GR (1979) N-Methyltaransferase and 7methyl- $N^{9}$-nucleoside hydrolase activity in Coffea arabi$\mathrm{ca}$ and the biosynthesis of caffeine. Phytochemistry 18: 451-455.

Scheline RR (1991) CRC Handbook of mammalian metabolism of plant compounds. CRC Press, Boca Raton, Florida, pp 1-514

Shimizu MM, Mazzafera P (2000) A role for trigonelline during imbibition and germination of coffee seeds. Plant Biol. 2: 605-611.

Suzuki T, Ashihara H, Waller GR (1992) Purine and purine alkaloid metabolism in Camellia and Coffea plants. Phytochemistry 31: 2575-2584.

Suzuki T, Waller GR (1984) Biosynthesis and biodegradation of caffeine, theobromine, and theophylline in Coffea arabica L. fruits. J.Agric. Food Chem. 32: 845-848.

Taguchi H, Nishitani H, Okumura K, Shimabayashi Y, Iwai K (1989) Biosynthesis and metabolism of trigonelline in Lemna paucicostata 151. Agric. Biol. Chem. 53: 2867-2871

Taguchi H, Sakaguchi M, Yamaki K, Shimabayashi Y (1987) Biosynthesis of trigonelline in the coffee plant. Nippon Nogeikagaku Kaishi 61: 183-189 
Taguchi H, Shimabayashi Y (1983) Findings of trigonelline demethylating enzyme activity in various organisms and some properties of the enzyme from hog liver. Biochem. Biophys. Res. Commun. 113: 569-574.

Uefuji H, Ogita S, Yamaguchi Y, Koizumi N, Sano H (2003) Molecular cloning and functional characterization of three distinct $N$-methyltransferases involved in the caffeine biosynthetic pathway in coffee plants. Plant Physiol. 132: 372-380.

Upmeier B, Gross W, Koster S, Barz W (1988) Purification and properties of $S$-adenosyl-1-methionine:nicotinic acid- $N$ methyltransferase from cell suspension cultures of Glycine $\max$ L. Arch. Biochem. Biophys. 262: 445-454.

Wagner KG, Backer AI (1992) Dynamics of nucleotides in plants studied on a cellular basis. In: Jeon KW, Friedlander M (eds), Int. Rev. Cytol., Vol. 134, pp. 1-84. Academic Press, San Diego.

Wagner R, Feth F, Wagner KG (1986) The pyridine-nucleotide cycle in tabacco: Enzyme activities for the recycling of NAD. Planta 167: 226-232.
Willeke U, Heeger V, Meise M, Neuhann H, Schindelmeiser I, Vordemfelde K, Barz W (1979) Mutually exclusive occurrence and metabolism of trigonelline and nicotinic acid arabinoside in plant cell cultures. Phytochemistry 18: 105-110.

Yang KS, Waller GR (1965) Biosynthesis of the pyridine ring of ricinine from quinolinic acid glycerol and aspartic acid. Phytochemistry 4: 881-889.

Zheng XQ, Nagai C, Ashihara H (2004) Pyridine nucleotide cycle and trigonelline ( $N$-methylnicotinic acid) synthesis in developing leaves and fruits of Coffea arabica. Physiol. Plant. 122: 401-411.

Zheng XQ, Ashihara H (2004) Distribution, biosynthesis and function of purine and pyridine alkaloids in Coffea arabica seedlings. Plant Sci. 166: 807-813.

Zheng XQ, Hayashibe E, Ashihara H (2005) Changes in trigonelline ( $N$-methylnicotinic acid) content and nicotinic acid metabolism during germination of mungbean (Phaseolus aureus) seeds. J. Exp. Bot. 56: 1615-1623. 